\title{
Development and Psychometric Properties of Sexual and Reproductive Health Literacy Instrument for Infertile Women (SRH-Life): A Mixed Method Study
}

\section{Zahra Rakhshaee}

Islamic Azad University Rasht Branch https://orcid.org/0000-0002-9792-153X

\section{Zohreh Khakbazan}

Tehran University of Medical Sciences

Saharnaz Nedjat Saharnaz Nedjat

Tehran University of Medical Sciences

Raziyeh Maasoumi ( $\square$ r_masoumi@sina.tums.ac.ir)

https://orcid.org/0000-0002-4986-4104

\section{Research article}

Keywords: Reproductive health, Sexual health, Health literacy, questionnaire, Psychometric properties

Posted Date: August 3rd, 2020

DOI: https://doi.org/10.21203/rs.3.rs-50092/v1

License: (c) (i) This work is licensed under a Creative Commons Attribution 4.0 International License.

Read Full License 


\section{Development and psychometric properties of sexual and reproductive health literacy instrument for infertile women (SRH-Life): a mixed method study}

\section{Zahra Rakhshaee}

Ph.D Candidate in Reproductive Health, Department of Nursing and Midwifery, Rasht branch, Islamic Azad University, Rasht, Iran \& Department of Reproductive Health, School of Nursing and Midwifery, Tehran University of Medical Sciences, Tehran, Iran rakhshaeez@yahoo.com

\section{Zohreh Khakbazan}

Assistant Professor, Department of Reproductive Health, School of Nursing and Midwifery, Tehran University of Medical Sciences, Tehran, Iran

khakbaza@sina.tums.ac.ir

\section{Saharnaz Nedjat}

Professor, Epidemiology and Biostatistics Department, School of Public Health, Tehran University of Medical Sciences, Tehran, Iran

$\underline{\text { nejatsan@tums.ac.ir }}$

Raziyeh Maasoumi* (Corresponding author)

Assistant Professor, Department of Reproductive Health, Nursing and Midwifery Care Research Center, School of Nursing and Midwifery, Tehran University of Medical Sciences, Tehran, Iran

r_masoumi@sina.tums.ac.ir 


\begin{abstract}
Background: Promoting sexual- reproductive health literacy is one of the most important strategies for achieving the goals of sexual- reproductive health in different groups of women. Infertile women are one of the most vulnerable groups to the adverse effects of low levels of health literacy. Since no specific instrument exists for assessing the level of sexual- reproductive health literacy, therefore, this study aimed to develop and evaluate the psychometric characteristics of an instrument for measuring sexual and reproductive health literacy among infertile women (Sexual and Reproductive Health Literacy instrument for infertile women: SRH-Life).
\end{abstract}

Methods: This was a mixed method study with exploratory design which conducted from July 2018 to Jan 2020 in northern Iran. Semi structured interviews with infertile women, literature review and, expert panel comments were utilized to generate an item pool. Then, the psychometric properties of the instrument, validity and reliability were assessed.

Results: The initial instrument contained 78 items. Next, 10 experts evaluated content validity. Some items were removed and a provisional version of the instrument with 47 items was provided. Then, the face validity was performed by 10 infertile women. Finally, a random sample of 235 infertile women completed the instrument and construct validity were assessed. The exploratory factor analysis was performed, 35 items were loaded, which indicated a 4-factor solution for the instrument including reproductive health information ( 8 items), infertility and treatment information (9 items), sexual health information ( 8 items) and functional sexual- reproductive literacy (10 items) that jointly explained $55.3 \%$ of the variance observed. For reliability, internal 
consistency showed satisfactory results with Cronbach's alpha coefficients ranging from 0.89 to 0.9 . Intraclass correlation coefficient (test-retest analysis) showed acceptable stability for the instrument.

Conclusion: The results showed that Sexual and Reproductive Health Literacy instrument for infertile women (SRH-Life) is a valid and reliable measure for assessing sexual and reproductive health literacy among women with infertility.

Key words: Reproductive health; Sexual health; Health literacy; questionnaire; Psychometric properties. 


\section{Background}

According to the World Health Organization (WHO), "sexual- reproductive health literacy provides the ability to understand sexual- reproductive health information and act on existing information. Not only can it reduce the risk of HIV, HSV-2 and other STIs, unwanted pregnancies, maternal mortality, but also has yields multiple benefits beyond health" [1]. WHO considers health literacy as a cognitive and social skill that leads to the proper promotion and maintenance of people's health [2]. Promoting sexualreproductive health literacy is one of the most important strategies for achieving the goals of sexual- reproductive health in different groups of women [3, 4]. Sexualreproductive health literacy, by motivating and enabling people to access information, understand and use information, plays an important role in people's self-efficacy in adhering to a program for self-care, treatment, and solving health-related problems [2] and can help people express their ideas, feelings, values, questions and concerns and improve their access to health care services $[5,6]$.

The infertile women are one of the groups who need to have sexual-reproductive health literacy. They, like people with chronic diseases, are considered to be at risk for adverse effects of low levels of literacy [7]. Various studies have shown that most infertile women have little information about sexual- reproductive health and infertility treatments [8-10] and the lack of information, by creating or exacerbating anxiety in women, is an obstacle to infertility treatment [9]. Insufficient knowledge, due to insufficient health literacy, can affect people's self-efficacy and self-care, and people cannot take proper care of themselves [11]. Also, in infertile women, after diagnosis or during infertility treatments, problems occur in the sexual response cycle (desire, arousal, and orgasm) [12] and the need to implement a schedule for sexual intercourse 
and medical interventions causes sexual dysfunction in women [13]. Saheb al-Zamani et al (2018), showed that the level of health literacy in most Iranian couples with infertility was borderline that it had adverse effects on sexual function and sexual satisfaction [14]. Thus, having the desired level of sexual health literacy increases a person's ability to analyze, judge, discourse, make decisions, and change sexual behavior, enabling him or her to provide, maintain, and enhance sexual health $[15,16]$. In this regard, service providers to women with infertility should be aware of the limitations of their sexualreproductive health literacy, which also requires the availability of a valid and specific instrument. According to extensive literature review, there is no specific instrument for sexual- reproductive health literacy in infertile women in world. Therefore, this study was conducted with a combined approach (qualitative-quantitative) and with the aim of designing and psychometric evaluation of sexual and reproductive health literacy instrument in women with infertility in Iran, so that it can be used as a basis for evaluating, improving and promoting sexual and reproductive health literacy in women with infertility.

\section{Methods}

The present study is a sequential exploratory mixed method study of instrument development variant, which was conducted in the infertility centers in the city of Rasht (in the North of Iran) from July 2018 to Jan 2020. The present study was conducted in two stages, the qualitative stage for Item generation and the quantitative stage for measuring the psychometrically evaluate an instrument. 


\section{Stage 1: Item generation}

Qualitative study and a literature review were used to generate an item pool. A qualitative study with a conventional content analysis approach was conducted with the aim of exploring the understanding and experiences of women with infertility of the concept of sexual- reproductive health literacy. Purposive sampling was performed with maximum diversity in terms of age, education, employment status, social- economic status, cause of infertility and duration of infertility. Criteria for entering the study included Iranian women with primary and secondary infertility, willing to participate in research, able to understand, speak, communicate and interview in Persian. Specialized infertility centers in the city of Rasht (a city in northern Iran) were the setting of data collection. In-depth and semi-structured interviews with women with infertility and key informants were conducted individually and face-to-face in a private room at the Infertility Center. Sampling continued until the data was saturated, so that no new data from the interviews were obtained. Interviews were audio recorded with participants' permission. The duration of each interview varied from 30 to 90 minutes and averaged 45 minutes. Then, in the shortest possible time, after listening to the text of the interview several times, the interviews were transferred word for word on paper and finally typed. Data were analyzed by conventional content analysis. At this stage, items pool was extracted by inductive approach, based on the concepts explored in the content analysis of the qualitative study. Then, to complete the items using a deductive approach, all published studies in databases of Pubmed, Web of Science, ProQuest, MEDLINE, Google Scholar and dedicated sites of WHO and CDC were searched from 2000 to 2019 and different combinations of keywords, including sexual health, reproductive health, health literacy, women, infertility, questionnaire, validity, 
reliability, psychometric assessment, Qualitative/Mixed Method Studies were used. Therefore, using the inductive- deductive approach, the initial instrument of reproductive and sexual health literacy was designed and entered the second stage to evaluate psychometric properties.

\section{Stage 2: psychometric properties assessment}

At this stage of the study, content validity, face validity and construct validity were examined. Also, instrument reliability was assessed in terms of internal consistency and stability.

\section{Content validity}

Content validity was assessed in two quantitative and qualitative methods with the help of an expert panel consisting of 10 experts in the field of reproductive and sexual health, health promotion, health literacy and psychometrics. The validity of the qualitative content was examined in terms of the content of the items, the general structure of the questionnaire, the need to remove or add items, the appropriate position of items, the use of appropriate words, compliance with grammar and proper scoring of items. Quantitative content validity was assessed by calculating the content validity ratio (CVR) and content validity index (CVI). To assess content validity by CVR, 10 experts were asked to evaluate each item of the questionnaire according to a 3-point scale (necessary, useful but not necessary, not necessary) and the CVR was calculated for each item. According to Lawshe's table, items with CVR > 0.62 (based on 10 experts' evaluation) were kept [17].

To determine the content validity index (CVI), the opinions of 10 experts were examined to determine the relevance, clarity, and simplicity of each item according to 
the Waltz \& Bausell content validity index [18]. This index was evaluated in a 4-point Likert scale (very relevant, relevant, relatively relevant, and not relevant). If the score of the content validity index was higher than 0.79 , the item was considered appropriate [19].

\section{Face validity}

To determine the face validity of the instrument, 10 individuals of women with infertility were selected using a purposive sampling to verify the clarity, relevance and difficulty of each item.

\section{Construct validity}

To perform construct validity, 235 women with infertility completed the questionnaire. Participants were available through infertility clinics and they were recruited directly. The sample size was determined as the number of items in the instrument (47 items) multiplied by 5 [20]. At this stage, convenience sampling was used and the criteria for entering the study included women with primary and secondary infertility, a willingness to participate in the study, and a minimum of literacy. First, demographic data and participants' infertility status were recorded. Then, the questionnaires, in the form of a 5-point Likert scale, were completed as Self-administered. The data were collected by the researcher, and when the questionnaire was delivered, the researcher reviewed it so that no question remained unanswered. After entering the data, SPSS 23 software was used for statistical analysis.

In the present study, the construct validity was examined using Exploratory Factor Analysis (EFA) with varimax rotation with the aim of identifying the dimensions of the questionnaire. The Kaiser Meyer-Olkin (KMO) and Bartlett's Test of Sphericity were 
performed to determine the appropriateness of the sample for factor analysis $[21,22]$. Eigenvalues above 1 and factor loadings greater than or equal to 0.30 were considered appropriate to verify the number of possible underlying factors. To achieve the most desirable number of factors, the share of total variance expressed, scree plot and eigenvalue, were considered.

\section{Reliability}

In this study, the reliability of the questionnaire was assessed by examining the internal consistency and repeatability. To examine the internal consistency, Cronbach's alpha coefficient (acceptable level of above 0.7) was calculated for each dimension and the whole scale [23]. To assess the questionnaire's time stability, the Intraclass Correlation Coefficient (ICC) was calculated by performing test-retest analysis. For this purpose, 20 infertile women completed the questionnaire twice in 2-week intervals. The ICC of 0.75 or higher were considered satisfactory [24].

\section{Ethical considerations}

This study was approved by the Ethics Committee of Faculty of Nursing and Midwifery of Tehran University of Medical Sciences (ethics code:IR.TUMS.FNM.REC.1397.066). A written consent letter was obtained from all participants and interviews were conducted in a private room in the infertility centers. Maintaining anonymity and confidentiality of the data were collected and analyzed. 


\section{Results}

Qualitative data were obtained through 19 in-depth and semi-structured interviews, including interviews with 16 women with infertility and 3 key informants (1 gynecologist and infertility specialist, 2 counseling midwives of the infertility Center). Infertile women in this study ranged in age from 27 to 44 years. Of the 16 women with infertility, 11 had primary infertility and 5 had secondary infertility. The texts were read several times to get a general concept. The meaning units were identified and then the related ones were compressed and achieved codes. Codes were categorized into categories and subcategories. Finally, 6 themes (reproductive health information needs, sexual health information needs, information seeking, understanding, validating and consciously using information) emerged.

In total, from the results of the content analysis of the interviews (165 items) and extensive literature review (4 items), items pool, consisting of 169 items, was compiled, which was reduced to 78 items after review in the research group. Then, the 78 -item instrument designed to check the content validity, face validity, construct validity and reliability entered the second stage.

\section{Content validity}

In qualitative content validity, comments and recommendations of 10 reproductive and sexual health experts were performed. The modifications were implemented at this phase of assessment that the most important of which was the separation of long items and simplification of item. Therefore, by separating the items, 2 items were added to the questionnaire. Then, the 80-item questionnaire was completed by 10 experts for assessment of CVR and CVI. The minimum accepted CVR score on the Lawshe table 
was 0.62 . Accordingly, 33 items were removed and finally 47 items remained to enter the next stage to determine the CVI. By assessment CVI, all items received an acceptable score and no items were removed. Also, the average of scores for content validity index (S-CVI/Ave) was calculated and the score was 0.965, which was acceptable considering that its value is higher than the standard value of 0.9.

\section{Face validity}

To assess the face validity, 10 women with infertility were selected using a purposive sampling to verify the clarity, relevance and difficulty of understanding each item. Therefore, 7 items was reworded or modified, and the questionnaire entered the stage of construct validity with 47 items.

\section{Construct validity}

Exploratory factor analysis was performed on data from 235 infertile women, of whom $63.4 \%$ had primary infertility and $36.6 \%$ had secondary infertility. The average age of the participating women was $30.8 \pm 6.1$ with a range of 20 to 48 years; The average duration of marriage was $7.8 \pm$ with a range of 1 to 30 years and the average duration of infertility was 4.5 with a range of 1 to 28 . Table- 1 shows the characteristics of the participants.

The adequacy of sample size was confirmed by Kaiser-Meyer-Olkin (KMO) and Bartlett's Test of Sphericity $\left(\mathrm{KMO}=0.945\right.$ and $\left.\chi^{2}=5687.244, \mathrm{p}=0.000\right)$. The results showed that the correlations between items were large enough to perform exploratory factor analysis. 
The initial analysis indicated a 6-factor solution with eigenvalues greater than 1 that jointly accounted for $59.4 \%$ of the variance observed. After assessment, two factors were excluded for the following reasons:

a. There was factor 6 with two items more relevant to sexual health information and thus the factor was excluded and the items conjugated to factor 2 (sexual health information).

b. Item loading on factor 5 did not satisfy the expected threshold. 3 items with low loading were relevant to infertility but Item loading on factor 1 (infertility and treatment information) satisfied the expected threshold.

Finally, based on the exploratory factor analysis using Maximum Likelihood method, the questionnaire items were placed in 4 factors with eigenvalues greater than 1 , that jointly accounted $55.34 \%$ of the total variance. The factor loading of each item in the factor matrix and the rotated matrix was considered to be at least 0.3 . Accordingly, 12 items were removed and the number of items was reduced from 47 items to 35 items. Eventually, a sexual- reproductive health literacy questionnaire was designed in infertile women with 35 items on 4 factors including reproductive health information ( 8 items), infertility and treatment information (9 items), sexual health information (8 items) and functional reproductive-sexual literacy (10 items). Table- 2 shows the factor loading of the items after rotation and in the relevant domains.

\section{Reliability}

Reliability of the questionnaire was assessed by estimating the Cronbach's alpha coefficient. The results showed that all factors had acceptable internal consistency. The Cronbach's alpha coefficient for each subscale and the questionnaire as a whole ranged 
from 0.89 to 0.91 . The time stability of the questionnaire and its sub-scales as measured by the ICC was found to be satisfactory (ranges from 0.82 to 0.94 ) and they were above acceptable threshold (Table-3).

\section{Discussion}

The present study is the first study to design and assess the psychometric properties an instrument for measuring sexual and reproductive health literacy in women with infertility. The initial instrument was designed based on data from a qualitative study of infertile women, expert opinions, and extensive literature review on health literacy. The designed instrument includes a range of questions to assess reproductive health literacy and sexual health literacy. The results showed that the SRH-Life is a valid instrument for measuring sexual and reproductive health literacy among women with infertility. Also, the multidimensional structure of the designed questionnaire is one of its strengths. The questionnaire consisted of 35 questions and was developed in 4 dimensions, including reproductive health information, infertility and treatment information, sexual health information, and sexual- reproductive functional literacy, which were completed as self-administrating. Because most participants completed the questionnaire within 15 minutes, the questionnaire could be easily used for screening. One of the strengths of this instrument is that by removing the dimension of "Infertility and Treatment Information" consisting of 9 items and removing an item related to infertility (Question 29) related to the dimension of functional literacy, it can be used as an instrument to measure sexual- reproductive health literacy in women of reproductive ages (consisting of 25 questions). 
Measuring health literacy is essential to prevent of the dangers of limited literacy by awareness and or designing specific interventions to increase it [25]. Since the introduction of health literacy, researchers have developed a variety of tools for measuring health literacy, the most widely used of which are the rapid estimate of adult literacy in medicine $(\text { REALM })^{6}$ test of functional health literacy in adults (TOFHLA) ${ }^{7}$, and the newest vital sign $(\mathrm{NVS})^{8}[26]$. Most health literacy studies examine general health literacy and do not focus on specific areas [27].

Women's sexual- reproductive health literacy is a new topic and although many studies have identified health literacy in women's reproductive health as important [28], few studies have been conducted in this area. In this regard, Masoumi et al. (2019) designed an instrument for measuring the sexual health literacy of Iranian adults (men and women over the age of 18) that included 40 questions in 4 dimensions including access (7 items), reading and comprehension (18 items), evaluation and analysis (5 items), information usage (10 items) and literature review was used to design the initial items of the instrument [29]. Sexual health literacy for adults (SHELA) questionnaire, like most health literacy instruments, including health literacy assessment instruments in Iranian adolescents [30], health literacy instruments for married immigrant women in South Korea [31] and health literacy instruments for women with breast cancer [32] were designed based on the dimensions of health literacy. Dimensions of access, understanding, evaluation and judgment, decision-making and behavior are the main foundations of health literacy in definitions [33]. In the present instrument, the domain of functional sexual- reproductive literacy consisting of 10 items examines women's ability to access and search, understand and evaluate, evaluate and use the information of sexual- reproductive health. 
The questions of the present instrument were extracted from a qualitative study based on in-depth interviews, during the factor analysis, the dimensions of reproductive health information, infertility and treatment information and sexual health information were obtained, which can examine the knowledge and the most important information needs of reproductive and sexual in women with infertility. Compared to other studies, the factor analysis structure in the present instrument has a more diverse range and due to the presence of more than 3 items in each factor, it has a more stable and reliable structure [34]. The ability of the instrument present in examining the various dimensions of reproductive and sexual health literacy, including relevant knowledge and information, is one of the strengths of this instrument. In this regard, the Maternal Health Literacy Assessment Instrument designed by Dia et al. (2014) and the McCatherine et al. (2011) Prenatal Health Literacy Instrument evaluate the health knowledge dimension and information related to maternal health [35, 36].

Sorensen et al. (2016) provided a conceptual framework for health literacy consisting of 12 dimensions in which knowledge was introduced as the first dimension of health literacy [37]. Also, Edwards et al. (2012) proposed 5 steps in the designed model of Health Literacy Road, the first step of which was health knowledge, so that a person's basic knowledge of health and health concerns is formed through reading, interacting with health professionals or health care providers, discussing with friends and family, and providing health information from the media, and the individual can increase health knowledge in the later stages by developing health literacy skills and practices, including information seeking, comprehension, etc., and ultimately lead to conscious decision-making and appropriate action [38]. 
Health literacy is the individual, cognitive, and social skills that determine a person's ability to access, understand, and use information to maintain and promote desired health and improve knowledge and understanding of health components and change attitudes and motivations related to health behavior and improve self-efficacy in relation to certain tasks [39]. Therefore, by recognizing the dimensions of sexual- reproductive health in women through a special and comprehensive instrument, health care providers and specialists can provide the required information in accordance with the facilities and understanding of women. As a result of better interaction with health care providers, women's participation in the decision-making process of treatment and self-care methods will lead to optimal treatment outcomes and the promotion of women's sexual and reproductive health.

\section{Limitations:}

To measure how valid of instrument, it is necessary to compare the results of measurements with other recognized instruments. Therefore, it is recommended that concurrent or criterion validity of the instrument be investigated in future studies. Also, the instrument was tested in one location using a cross-sectional approach and stability (test-retest analysis) was examined in a separate sample.

\section{Conclusion}

The Sexual and Reproductive Health Literacy instrument for infertile women (SRHLife) is a valid and reliable instrument that, in addition to assessing the level of sexual and reproductive health literacy that can identify the information needs and barriers to promoting sexual and reproductive health literacy in infertile women so that planning 
and necessary interventions can be done accordingly. It is also a short and easy-to-use instrument that is suggested for assessing the level of sexual and reproductive health literacy of women with infertility in future studies. In addition, it is possible that by eliminating infertility and treatment information dimension, it could be used to assess sexual and reproductive health literacy in other women of reproductive ages. Because this instrument examines the most important issues of sexual and reproductive health in women.

\section{Abbreviations}

SRH-Life: Sexual and Reproductive Health Literacy instrument for infertile women; WHO: World Health Organization; CVR: Content Validity Ratio; CVI: Content Validity Index; EFA: Exploratory Factor Analysis; KMO: Kaiser Meyer-Olkin; ICC: Intraclass Correlation Coefficient; S-CVI: Scale level-CVI; REALM: Rapid Estimate of Adult Literacy in Medicine; TOFHLA: Test of Functional Health Literacy in Adults; NVS: Newest Vital Sign; SHELA: Sexual health literacy for adults.

\section{Ethics approval and consent to participate}

This study was approved by the Ethics Committee of Faculty of Nursing and Midwifery of Tehran University of Medical Sciences (ethics code:IR.TUMS.FNM.REC.1397.066). A written consent letter was obtained from all participants and interviews were conducted in a private room in the infertility centers. Maintaining anonymity and confidentiality of the data were collected and analyzed.

\section{Consent for publication}

Not applicable.

\section{Availability of data and materials}

The data set are available from the corresponding author on reasonable request. 


\section{Competing interests}

The authors declare that they have no competing interests.

\section{Funding}

The present study was Ph.D. thesis of the first author and was funded by the Tehran University of Medical Sciences.

\section{Authors' contributions}

All the authors contributed to the conception and design of the study. ZR collected and analyzed the data and wrote first version of the manuscript. ZK and RM supervised the study and participated in all part of study including designing the study, data analysis and manuscript writing. SN contributed in data analysis of quantitative phase and evaluated the manuscript. All authors approved the final version.

\section{Acknowledgements}

This article is a part of the Ph.D thesis in reproductive health that is approved by the Tehran University of Medical Sciences. The authors would like to thank the research deputy of the nursing and midwifery faculty of Tehran University of Medical Sciences, the manager of the Mehr Infertility and Medical Institute of Rasht, Dr. Mehr Afza, Research deputy of the Gilan University of Medical Sciences and participants for their sincere cooperation.

\section{References}

1. World Health Organization. Sexual and reproductive health literacy and the SDGs. 2016. Available from: http://www.who.int/healthpromotion/conferences/9gchp/sexual-reproductive-healthliteracy/en/.

2. Organization WH. Division of health promotion, education and communications health education and health promotion unit. Health promotion glossary. 1998;10.

3. Sexual E. reproductive health needs analysis: findings and recommendations Melbourne: Women's Health East; 2016 (cited Jun2016).

4. Shieh C, Halstead JA. Understanding the impact of health literacy on women's health. Journal of Obstetric, Gynecologic \& Neonatal Nursing. 2009;38:601-12.

5. Family Care International I. Millennium Development Goals \& Sexual \& Reproductive Health: Briefing Cards: Family Care International; 2005. 
6. Organization WH. Framework of Actions for the follow-up to the Programme of Action of the International Conference on Population and Development Beyond 2014: Report of the Secretary General. Reproductive Health Matters. 2015;23:155-8.

7. Kindig DA, Panzer AM, Nielsen-Bohlman L. Health literacy: a prescription to end confusion: National Academies Press; 2004.

8. Vedadhir A, Rahmani M, Dabbagh T. Infertility as a Socio-cultural Issue: Understanding and Lived Experience of Infertile Women Seeking Treatment. Journal of Social Problems of Iran. 2017;7:15975.

9. Dyer SJ, Abrahams N, Hoffman M, van der Spuy ZM. Infertility in South Africa: women's reproductive health knowledge and treatment-seeking behaviour for involuntary childlessness. Human reproduction. 2002;17:1657-62.

10. Bennett LR. Infertility, womanhood and motherhood in contemporary Indonesia: understanding gender discrimination in the realm of biomedical fertility care. Intersections: Gender and Sexuality in Asia and the Pacific. 2012;28.

11. Aghamohammdian Sharbaf HR, Zarezade Kheibari S, Horouf Ghanad M, ME. HA. The relationship between perfectionism and sexual function in infertile women. The Iranian Journal of Obstetrics, Gynecology and Infertility. 2014;17:9-17.

12. Bokaie M, Yassini Ardekani SM, Alavi-Majad H. Does infertility influence couples' relationships? A qualitative study. Journal of Qualitative Research in Health Sciences. 2017;6:63-77.

13. Read J. Sexual problems associated with infertility, pregnancy, and ageing. Bmj. 1999;318:5879.

14. Sahebalzamani M, Mostaedi Z, Farahani H, Sokhanvar M. Relationship between health literacy and sexual function and sexual satisfaction in infertile couples referred to the Royan Institute. International journal of fertility \& sterility. 2018;12:136.

15. Gilbert M, Ferlatte O, Michelow W, Martin S, Young I, Donelle L, et al. P02. 05 Sexual health literacy-an emerging framework for research and intervention to improve sexual health for gay men. BMJ Publishing Group Ltd; 2015.

16. Bongaarts J. World Health Organization Health in 2015: From MDGs, Millennium Development Goals, to SDGs, Sustainable Development Goals Geneva: WHO Press, 2016. 212 p. Population and Development Review. 2016;42:575.

17. Lawshe CH. A quantitative approach to content validity. Personnel psychology. 1975;28:563-75.

18. Lynn MR. Determination and quantification of content validity. Nursing research. 1986.

19. Hyrkäs K, Appelqvist-Schmidlechner K, Oksa L. Validating an instrument for clinical supervision using an expert panel. International Journal of nursing studies. 2003;40:619-25.

20. Floyd FJ, Widaman KF. Factor analysis in the development and refinement of clinical assessment instruments. Psychological assessment. 1995;7:286.

21. Nunnally JC. Psychometric theory 3E: Tata McGraw-hill education; 1994.

22. Harrington D. Confirmatory factor analysis: Oxford university press; 2009. 
23. Santos JRA. Cronbach's alpha: A tool for assessing the reliability of scales. Journal of extension. 1999;37:1-5.

24. Shoukri MM. Measures of interobserver agreement and reliability: CRC press; 2010.

25. Weiss BD, Mays MZ, Martz W, Castro KM, DeWalt DA, Pignone MP, et al. Quick assessment of literacy in primary care: the newest vital sign. The Annals of Family Medicine. 2005;3:514-22.

26. Tavousi M, Ebadi M, Fattahi E, Jahangiry L, Hashemi A, Hashemiparast M, et al. Health literacy measures: A systematic review of the literature. Payesh (Health Monitor). 2015;14:485-96.

27. UNFPA. International- Conference-on-Populationand- Development 1994. Available from: http://www.unfpa.org/public/home/sitemap/icpd/International-Conference-on-Population-and-

Development.

28. Kilfoyle KA, Vitko M, O'Conor R, Bailey SC. Health literacy and Women's reproductive health: a systematic review. Journal of Women's Health. 2016;25:1237-55.

29. Maasoumi R, Tavousi M, Zarei F. Development and psychometric properties of sexual health literacy for adults (SHELA) questionnaire. Journal of hayat. 2019;25:56-69.

30. Ghanbari S, Ramezankhani A, Mehrabi Y, Montazeri A. The health literacy measure for adolescents (HELMA): development and psychometric evaluation. Payesh (Health Monitor). 2016;15:404-10.

31. Yang SJ, Chee YK. Development and psychometric testing of the health literacy index for female marriage immigrants [HLI-FMI] in Korea. Women \& health. 2017;57:1007-30.

32. Khalili S, Tavousi M, Banaem LM. Health Literacy for women with breast cancer (HELBA): development and psychometric properties. Payesh (Health Monitor). 2017;16:359-66.

33. Tavousi M, Ebadi M, Azin A, Shakerinejad G, Hashemi A, Fattahi E, et al. Definitions of health literacy: a review of the literature. Payesh (Health Monitor). 2014;13:119-24.

34. Costello AB, J. O. Best practices in exploratory factor analysis: Four recommendations for getting the most from your analysis. Practical assessment, research, and evaluation. 2005;10.

35. Dai C, Yan J, Xu L, X. Q. Item selection for perinatal maternal health literacy scale. . Journal of Central South University Medical Sciences. 2015;40:558-63.

36. McCathern RM. Exploring the Predictive Relationship Between General Health Literacy Levels and Prenatal Care Health Literacy Levels. 2011.

37. Sørensen K, Van den Broucke S, Fullam J, Doyle G, Pelikan J, Slonska Z, et al. Health literacy and public health: a systematic review and integration of definitions and models. BMC public health. 2012;12:80.

38. Edwards M, Wood F, Davies M, Edwards A. The development of health literacy in patients with a long-term health condition: the health literacy pathway model. BMC public health. 2012;12:130.

39. Berkman ND, Davis TC, McCormack L. Health literacy: what is it? Journal of health communication. 2010;15:9-19. 
Table 1: Characteristics of the study participants $(n=235)$

\begin{tabular}{|l|l|}
\hline & No. [\%] \\
\hline Age groups (years) & $25(10.7)$ \\
$20-24$ & $68(29.1)$ \\
$25-29$ & $65(27.3)$ \\
$30-34$ & $47(20)$ \\
$35-39$ & $24(10.3)$ \\
$40-44$ & $6(2.6)$ \\
$\geq 45$ & \\
\hline Education level & \\
Less than high school & $23(17.9)$ \\
High school & $9(3.8)$ \\
High school diploma & $94(40.0)$ \\
Associate degree & $22(9.4)$ \\
Bachelor's degree & $57(24.3)$ \\
Graduate degree & $28(11.9)$ \\
PhD & $2(0.9)$ \\
\hline Occupation & \\
Housewife & $174(74.0)$ \\
Employed & $61(26.6)$ \\
\hline Socio-economic status (Self-expression) & \\
Top & \\
higher than average & $4(1.7)$ \\
medium & $40(17.0)$ \\
Medium to low & $149(63.4)$ \\
Down & $33(14.0)$ \\
& $9(3.8)$ \\
\hline The type of infertility & \\
Primary infertility & \\
Secondary infertility & \\
\hline Cause of infertility & \\
Female & $149(63.4)$ \\
Male & $86(36.6)$ \\
Female- Male & \\
Dnknown cause & \\
\hline History of infertility treatment & \\
\hline Nos & \\
\hline
\end{tabular}




\section{Table 2: The results obtained from exploratory factor analysis using varimax rotation for the SRH-Life}

\begin{tabular}{|c|c|c|c|c|}
\hline Item & $\begin{array}{l}\text { Factor 1 } \\
\text { (Infertility } \\
\text { and treatment } \\
\text { information) }\end{array}$ & $\begin{array}{l}\text { Factor } 2 \\
\text { (Sexual health } \\
\text { information) }\end{array}$ & $\begin{array}{l}\text { Factor 3 } \\
\text { (Functional } \\
\text { sexual- } \\
\text { reproductive } \\
\text { literacy) }\end{array}$ & $\begin{array}{l}\text { Factor } 4 \\
\text { (Reproductive } \\
\text { health } \\
\text { information) }\end{array}$ \\
\hline $\begin{array}{l}\text { 1- I know about women's reproductive organs, such as the } \\
\text { uterus, fallopian tubes, and ovaries. }\end{array}$ & & & & 0.633 \\
\hline 2- I know about menstrual cycle and ovulation time. & & & & 0.723 \\
\hline $\begin{array}{l}\text { 3- I know about methods of ovulation timing determination, for } \\
\text { example, based on my menstrual history. }\end{array}$ & & & & 0.633 \\
\hline $\begin{array}{l}\text { 4- I have information about the reproductive process and how to } \\
\text { get pregnant. }\end{array}$ & & & & 0.577 \\
\hline $\begin{array}{l}\text { 5- I know about the role of age, health status, nutrition, exercise } \\
\text { and stress on female fertility. }\end{array}$ & & & & 0.368 \\
\hline $\begin{array}{l}\text { 6- I know about the effect of the right way of having sex, the } \\
\text { time of intercourse and its frequency, in order to increase the } \\
\text { chances of pregnancy. }\end{array}$ & & & & 0.537 \\
\hline $\begin{array}{l}\text { 7- I know about prenatal care, including folic acid intake, proper } \\
\text { nutrition, and ideal weight. }\end{array}$ & & & & 0.433 \\
\hline $\begin{array}{l}\text { 8- I know about the prevention of cancers of the reproductive } \\
\text { system, including Pap smear and mammogram. }\end{array}$ & & & & 0.469 \\
\hline $\begin{array}{l}\text { 9- I have information about when to see a doctor to start } \\
\text { infertility treatment. }\end{array}$ & 0.469 & & & \\
\hline 10- I know the cause of my infertility. & $\mathbf{0 . 4 2 0}$ & & & \\
\hline 11- I know about my infertility treatment. & 0.570 & & & \\
\hline $\begin{array}{l}\text { 12- I have information about infertility treatments such as IUI, } \\
\text { IVF (fetal implantation) and microinjection (micro). }\end{array}$ & 0.795 & & & \\
\hline $\begin{array}{l}\text { 13- I have information about infertility treatment using ovule } \\
\text { donation and embryo donation. }\end{array}$ & 0.706 & & & \\
\hline $\begin{array}{l}\text { 14- I know about the factors that contribute to the success or } \\
\text { failure of infertility treatment, such as age. }\end{array}$ & 0.704 & & & \\
\hline $\begin{array}{l}\text { 15- I know about the side effects of infertility treatments, such } \\
\text { as multiple pregnancy and ovarian hyper stimulation. }\end{array}$ & 0.644 & & & \\
\hline 16- I know about the side effects of my medications. & 0.623 & & & \\
\hline $\begin{array}{l}\text { 17- I know about the effects of infertility on couples' sexual } \\
\text { relationships. }\end{array}$ & 0.507 & & & \\
\hline $\begin{array}{l}\text { 18- I have information about the stages of sexual intercourse, } \\
\text { such as starting with flirting and caressing. }\end{array}$ & & 0.678 & & \\
\hline $\begin{array}{l}\text { 19- I have information about the peak of sexual pleasure or } \\
\text { orgasm. }\end{array}$ & & 0.643 & & \\
\hline $\begin{array}{l}\text { 20- I know about the factors that affect the improvement of } \\
\text { sexual relations with one's spouse, such as talking about sexual } \\
\text { interests, meeting expectations and paying attention to each } \\
\text { other's sexual satisfaction. }\end{array}$ & & 0.770 & & \\
\hline $\begin{array}{l}21 \text { - I know about the importance of the role of sex in intimacy, } \\
\text { relaxation, vitality, and the continuity of cohabitation. }\end{array}$ & & 0.739 & & \\
\hline $\begin{array}{l}\text { 22- I know about the importance of following up and treating } \\
\text { sexual problems by seeing a specialist. }\end{array}$ & & 0.527 & & \\
\hline $\begin{array}{l}\text { 23- I know about sexually transmitted diseases such as } \\
\text { gonorrhea, genital warts, genital herpes, AIDS, hepatitis, ways } \\
\text { to transmission and prevent them. }\end{array}$ & & 0.471 & & \\
\hline 24- I have information about all kinds of contraceptive methods. & & $\mathbf{0 . 3 3 6}$ & & \\
\hline $\begin{array}{l}\text { 25- In order to perform better and take better care of myself, I } \\
\text { search for sexual and reproductive health information. }\end{array}$ & & 0.455 & & \\
\hline
\end{tabular}




\begin{tabular}{|c|c|c|c|c|}
\hline $\begin{array}{l}\text { 26- I can get the necessary information about sexual and } \\
\text { reproductive health from various sources. }\end{array}$ & & & 0.355 & \\
\hline $\begin{array}{l}27 \text { - It's easy for me to read about sexual and reproductive health } \\
\text { from a variety of sources. }\end{array}$ & & & 0.349 & \\
\hline $\begin{array}{l}\text { 28- Sexual and reproductive health information provided to me } \\
\text { by a doctor and midwife is understandable to me. }\end{array}$ & & & 0.665 & \\
\hline $\begin{array}{l}\text { 29- The information I find about the cause of my infertility from } \\
\text { various sources of information is understandable to me. }\end{array}$ & & & $\mathbf{0 . 5 8 9}$ & \\
\hline $\begin{array}{l}\text { 30- I understand the information about my treatment methods } \\
\text { and its related cares. }\end{array}$ & & & $\mathbf{0 . 7 3 2}$ & \\
\hline $\begin{array}{l}\text { 31- I find out about the reproductive organs of women, the } \\
\text { menstrual cycle and the time of ovulation. }\end{array}$ & & & $\mathbf{0 . 4 8 9}$ & \\
\hline $\begin{array}{l}\text { 32- I understand the information related to couple's sexual } \\
\text { relations. }\end{array}$ & & & 0.706 & \\
\hline $\begin{array}{l}\text { 33- I understand the information related to sexually transmitted } \\
\text { diseases and their prevention. }\end{array}$ & & & $\mathbf{0 . 6 2 3}$ & \\
\hline $\begin{array}{l}\text { 34- I can assess the accuracy of information about sexual and } \\
\text { reproductive health. }\end{array}$ & & & $\mathbf{0 . 4 5 1}$ & \\
\hline $\begin{array}{l}\text { 35- I use information about reproductive health and sexual } \\
\text { health. }\end{array}$ & & & 0.421 & \\
\hline Eigenvalue & 5.32 & 4.93 & 4.75 & 4.37 \\
\hline Explained Variance (\%) & 15.19 & $\mathbf{1 4 . 0 8}$ & $\mathbf{1 3 . 5 8}$ & 12.48 \\
\hline Cumulative Variance (\%) & 15.19 & 29.28 & 42.86 & 55.34 \\
\hline
\end{tabular}


Table 3: Cronbach's $\alpha$ coefficient and ICC for the SRH-Life and its subscales

\begin{tabular}{|l|c|c|c|}
\hline \multicolumn{1}{|c|}{ Domain } & $\begin{array}{l}\text { Number } \\
\text { of } \\
\text { items }\end{array}$ & $\begin{array}{l}\text { Cronbach's } \boldsymbol{\alpha} \\
\text { coefficient }\end{array}$ & $\begin{array}{l}\text { Intraclass Correlation } \\
\text { Coefficient (ICC) }\end{array}$ \\
\hline Reproductive health information & 8 & 0.91 & 0.91 \\
\hline Infertility and treatment information & 9 & 0.90 & 0.94 \\
\hline Sexual health information & 8 & 0.89 & 0.92 \\
\hline $\begin{array}{l}\text { Functional reproductive-sexual } \\
\text { literacy }\end{array}$ & 10 & 0.90 & 0.94 \\
\hline The scale & 35 & 0.96 & \\
\hline
\end{tabular}

